\title{
Is the rate of postoperative complications following laparoscopy-assisted gastrectomy higher in elderly patients than in younger patients?
}

Ki-Han Kim, Min-Chan Kim ${ }^{*}$ and Ghap-Joong Jung

\begin{abstract}
Background: With an increase in life expectancy, very elderly patients are presenting with gastric cancer more commonly than ever. The present study retrospectively analyzed the surgical outcomes of laparoscopy-assisted gastrectomy for gastric cancer in the young, elderly, and very elderly age groups.

Methods: The study group consisted of 1,055 patients who underwent laparoscopy-assisted gastrectomy between February 2002 and December 2012. We divided these patients into three groups; group 1 (young age, <65 years), group 2 (elderly age, 65-74 years), and group 3 (very elderly age, $\geq 75$ years).

Results: There were statistical differences in the rates of postoperative complications among the three groups $(P=0.008)$. However, when assessed according to the severity of postoperative complications based on the Clavien-Dindo classification, there was no statistical difference among the three groups $(P=0.562)$.

Conclusions: Laparoscopy-assisted gastrectomy for gastric cancer can be performed in very elderly patients. In analyzing studies of elderly patients with postoperative complications following the procedure, not only should the rate of postoperative complications be taken into consideration, but also the severity of any postoperative complications.
\end{abstract}

Keywords: Age, Gastrectomy, Laparoscopy, Postoperative complication

\section{Background}

According to the annual report of the Korea National Statistical Office in 2007, citing figures from the World Health Organization, the proportion of elderly people aged 65 years or more was $9.9 \%$ [1]. By 2018, the proportion of people older than 65 years in Korea is expected to exceed 14\% [2]. Life expectancy is currently 74.4 years for men and 81.8 years for women [3]. Korea has one of the highest incidences of gastric cancer in the world, with the elderly, who are most likely to be affected by gastric cancer, representing the fastest growing group of the Korean population. The incidence of early gastric cancer, which is considered an appropriate indication for laparoscopy-assisted gastrectomy (LAG), is increasing in Korea because of recent

\footnotetext{
* Correspondence: mckim@donga.ac.kr

Department of Surgery, Dong-A University College of Medicine, 3-1 Dongdaeshin-Dong, Seo-Gu, Busan 602-715, Korea
}

improvements in early diagnosis and a well-developed mass-screening program $[4,5]$. As the mean age of the general population increases, an increase in numbers of elderly patients with gastric cancer can be expected, all of whom will be candidates for gastric resection.

LAG has been reported to be a less invasive surgical technique than open gastrectomy, with advantages that include good cosmetic effect, improved quality of life, minimal degree of pain, shorter hospital stay, early rehabilitation, and early return to social activity [6-8]. However, elderly patients are at high risk of intra- and post-operative complications owing to the high prevalence of comorbidities and decreased functional reserve in these patients. Many retrospective studies have evaluated gastrectomy in elderly patients with regard to feasibility and safety [9-11]. Several studies have also evaluated patients over 85 years old $[12,13]$. 
In this study, the authors aimed to investigate whether the use of LAG for gastric cancer can be extended to very elderly patients. In addition, the clinicopathological characteristics and surgical outcomes of gastric cancer were compared among three groups of patients (young, elderly, and very elderly) to determine the feasibility of LAG for very elderly patients.

\section{Methods}

\section{Patient collection}

From February 2002 through to December 2012, 1,055 consecutive patients who underwent LAG with lymph node dissection were enrolled in this study. In the initial early period of the study, the indication for LAG for gastric cancer was cT1N0M0. In 2006, the indication for LAG was extended to T2N1M0. Our surgical technique employed for laparoscopy-assisted distal gastrectomy has been described in detail in a previous report [14].

We gave information to the patients and obtained written consent from them for their operations. All patients underwent pre-operative evaluation, including gastrofiberoscopy and computed tomography of the abdomen and pelvis. Those over 70 years of age, or who had heart problems, were evaluated with echocardiography. At-risk cases with pulmonary conditions underwent pulmonary function testing. In some cases, endoscopic ultrasonography was performed to assess the depth of cancer invasion.

According to the 2007 annual report of the Korea National Statistical Office, elderly patients are defined as those aged 65 years more [1]. Therefore, for the purposes of comparison, we divided enrolled patients into three age groups: group 1 (young age, $<65$ years), group 2 (elderly age, 65-74 years), and group 3 (very elderly age, $\geq 75$ years). Clinicopathological characteristics and surgical outcomes of gastric cancer were compared among the three groups.

\section{Data collection}

We prospectively collected data from our gastric cancer database and retrospectively reviewed the medical records. Clinicopathologic features such as age, gender, body mass index (BMI), comorbidity disease, tumor size, histologic type, tumor location, gastric resection type, reconstruction type, $\mathrm{T}$ stage, $\mathrm{N}$ stage, retrieved lymph node, and TNM stage were compared among the three groups. In addition, post-operative outcomes, hospital course, post-operative morbidity, and post-operative mortality were evaluated.

In this study, gastric cancer stage was classified according to the 7th edition of the American Joint Committee on Cancer staging criteria [15]. The patients enrolled in this study underwent standard D2 or above, according to the 2010 Japanese gastric cancer treatment guidelines (ver.3) [16]. All the values were expressed as means \pm standard deviations.
All follow-up patients were monitored post-operatively by a routine check for blood tests, tumor markers (alphafetoprotein, carcinoembryonic antigen, and carbohydrate antigen 19-9), chest radiography, endoscopy, and computed tomography every 6 months for 2 years, then every year for the next 3 years.

\section{Definition of complications}

Operative mortality was defined as death within 30 days of surgery. Morbidities were defined as complications that required additional treatment after surgery. Initially, we collected data on postoperative complications among the three groups. Next, for standardization, these complications were graded according to the Clavien-Dindo classification, which was adopted using objective criteria to assess the severity and incidence of postoperative complications $[17,18]$.

\section{Standardized postoperative protocol}

All patients were managed routinely by a standardized peri-operative protocol, as follows: i) no nasogastric intubation or pre-operative mechanical bowel preparation; ii) minimal spillage of gastric contents; iii) use of two closed suction drains; iv) in case of subtotal gastrectomy, sips of water $48 \mathrm{~h}$ post-operatively; v) in case of total gastrectomy, sips of water $72 \mathrm{~h}$ post-operatively; vi) a clear liquid diet for 3 days (subtotal gastrectomy) or 4 days (total gastrectomy) post-operatively; vii) hospital discharge 7 or 8 days after a soft diet with no abnormal clinical symptoms.

\section{Statistical analysis}

The data were analyzed by Student's $t$-test or MannWhitney U-test, in addition to the $\chi^{2}$ test, and Fisher's exact test was used using SPSS version 18.0 (SPSS, Chicago, Ill, USA). Statistical significance was assumed for $P$ values $<0.05$.

\section{Results}

\section{Patient demographics}

The clinicopathologic features among the three groups are listed in Table 1 . There were no statistical differences in gender, BMI, tumor size, tumor location, $\mathrm{N}$ stage, and TNM stage. However, there was statistical significance with comorbidity, age, histologic type, and $\mathrm{T}$ stage $(P<0.001$, $P<0.001$, and $P<0.001$ ), respectively. In group 3 , there were more cases with advanced gastric cancer $(P=0.032)$.

\section{Postoperative surgical outcomes}

Table 2 shows the postoperative surgical outcomes. There were no statistical differences among the three groups except for retrieved lymph node and median follow-up duration $(P=0.002, P=0.033)$, respectively. Further, the median follow-up duration of group 3 was shorter than in the case of the other groups. 
Table 1 Clinicopathological features among the three groups

\begin{tabular}{|c|c|c|c|c|}
\hline & $\begin{array}{l}\text { Group } 1 \\
(n=672)\end{array}$ & $\begin{array}{l}\text { Group } 2 \\
(n=285)\end{array}$ & $\begin{array}{c}\text { Group } 3 \\
(n=98)\end{array}$ & $P$ value \\
\hline Age (year) & $51.3 \pm 8.9$ & $69.3 \pm 2.9$ & $77.6 \pm 2.6$ & $<0.001$ \\
\hline Gender (\%) & & & & 0.203 \\
\hline Male & $398(59.2)$ & $186(65.3)$ & $58(59.2)$ & \\
\hline Female & $274(40.8)$ & $99(34.7)$ & $40(40.8)$ & \\
\hline BMI $\left(\mathbf{k g} / \mathrm{m}^{2}\right)^{*}$ & $23.5 \pm 2.8$ & $23.2 \pm 3.0$ & $23.0 \pm 3.2$ & 0.253 \\
\hline Comorbidity (number,\%) & $171(25.4)$ & $141(49.5)$ & $66(67.3)$ & $<0.001$ \\
\hline Hypertension $^{* *}$ & 105 & 43 & 24 & \\
\hline Diabetes $^{* *}$ & 46 & 25 & 6 & \\
\hline Heart disease $e^{* *}$ & 20 & 10 & 3 & \\
\hline Pulmonary disease ${ }^{* *}$ & 10 & 12 & 2 & \\
\hline Liver disease ${ }^{* *}$ & 28 & 6 & 3 & \\
\hline Kidney disease & 2 & 1 & 0 & \\
\hline Others & 11 & 8 & 4 & \\
\hline Size of main lesion $(\mathrm{mm})^{*}$ & $2.8 \pm 1.9$ & $2.6 \pm 1.6$ & $3.0 \pm 2.2$ & 0.088 \\
\hline
\end{tabular}

Size of main lesion $(\mathbf{m m})^{*} \quad 2.8 \pm 1.9 \quad 2.6 \pm 1.6 \quad 3.0 \pm 2.2 \quad 0.088$

Histologic type

\begin{tabular}{|c|c|c|c|c|}
\hline Well differentiated & 129 & 98 & 26 & \\
\hline Moderately differentiated & 192 & 103 & 37 & \\
\hline Poorly differentiated & 253 & 71 & 26 & \\
\hline Signet ring cell & 82 & 5 & 2 & \\
\hline Other & 16 & 8 & 7 & \\
\hline Tumor location & & & & 0.283 \\
\hline Upper & 39 & 17 & 5 & \\
\hline Middle & 211 & 79 & 21 & \\
\hline Lower & 422 & 189 & 72 & \\
\hline $\operatorname{T~stage~}^{* * *}(\%)$ & & & & 0.032 \\
\hline EGC & $538(80.1)$ & $232(81.4)$ & $68(69.4)$ & \\
\hline AGC & $134(19.9)$ & $53(18.6)$ & $30(30.6)$ & \\
\hline $\mathrm{N}$ stage ${ }^{* * *}$ & & & & 0.260 \\
\hline NO & 573 & 249 & 79 & \\
\hline N1-N3 & 99 & 36 & 19 & \\
\hline Stage $\mathrm{e}^{* * *}$ & & & & 0.084 \\
\hline IA & 534 & 228 & 67 & \\
\hline IB & 41 & 22 & 11 & \\
\hline$\| \mathrm{A}$ & 32 & 18 & 9 & \\
\hline$\| \mathrm{B}$ & 25 & 11 & 5 & \\
\hline IIIA & 14 & 4 & 4 & \\
\hline$\||| B$ & 20 & 2 & 2 & \\
\hline$\||| C$ & 6 & 0 & 0 & \\
\hline
\end{tabular}

*All values are the means and standard deviations; ${ }^{* *}$ Combined number; ***Based on the AJCC 7th TNM classification.

Group 1: $<65$ years, young age; Group 2: 65-74 years, elderly age; Group 3: $\geq 75$ years, very elderly age.

\section{Postoperative morbidity and mortality}

In Table 3, group 1 had 62 complications after surgery (9.2\%), group 2 had 26 complications (9.1\%), and group 3 had 18 complications (18.4\%). In group 1, there were 5 major complications requiring re-operation (1 intraabdominal abscess, 4 duodenal stump leakages). There were 2 major complications with re-operation (1 duodenal stump leakage, 1 esophagojejunostomy leakage) and 2 mortalities (1 multi-organ failure, 1 duodenal stump leakage) in group 2 . In the case of the mortality with multi-organ failure, death occurred because of multi-organ failure after 28 postoperative days. This patient had a very complicated pre-operative history, with underlying pneumonia, atrial fibrillation, right middle cerebral artery infarction, and hypertension. He underwent laparoscopy-assisted distal gastrectomy (Billroth-I). After surgery, his condition necessitated removal to the intensive care unit; however, unfortunately, his cardiac, pulmonary, and renal functions gradually failed.

There was a statistical difference among the three groups $(P=0.008)$ in terms of post-operative complications. Group 3 had the highest proportion (18.4\%) of postoperative complications of the three groups. In group 3, there was one major complication (duodenal stump leakage) requiring re-operation. However, according to the Clavien-Dindo classification used to assess the severity and incidence of post-operative complications, there was no significant difference in minor and major complications among the three groups $(P=0.562)$ (Table 4).

\section{Discussion}

The average lifespan of Koreans is currently 74.4 years for men and 81.8 years for women. In 2030, the percentage of the population aged 65 and older in Korea is projected to exceed 20\% [19]. Gastric cancer is more prevalent in Korea than in western countries. Early gastric cancer is also found more frequently in Korea because of a well-developed mass-screening system [4,5]. In addition, laparoscopic procedures for early gastric cancer have been widely accepted in Korea [5]. The goals of laparoscopic surgery for gastric cancer are to minimize surgical insults and to maximize the patient's quality of life, while preserving the extent to which the tumor is removed and the appropriate negative margins achieved. Previous reports have demonstrated excellent short-term outcomes including less post-operative pain, improved cosmesis, early recovery, and improved quality of life [6-8].

Elderly patients are more likely to have concurrent medical conditions than are younger patients. Previous studies have shown that, as a result of comorbidity and decreased functional reserves, open gastric surgery in elderly patients is associated with increased morbidity and mortality rates, and a longer hospital stay [20,21]. In a study of laparoscopic 
Table 2 Postoperative outcomes

\begin{tabular}{|c|c|c|c|c|}
\hline & Group $1(n=672)$ & Group $2(n=285)$ & Group $3(n=98)$ & $P$ value \\
\hline Operative time (minutes)* & $204.0 \pm 55.5$ & $204.8 \pm 60.4$ & $193.1 \pm 62.1$ & 0.183 \\
\hline \multicolumn{5}{|l|}{ Hospital stay (days)* } \\
\hline with complication & $7.9 \pm 6.9$ & $7.7 \pm 5.4$ & $9.2 \pm 9.5$ & 0.133 \\
\hline without complication & $7.2 \pm 2.1$ & $7.0 \pm 1.5$ & $7.2 \pm 1.3$ & 0.474 \\
\hline Type of gastrectomy & & & & 0.693 \\
\hline Total & 48 & 24 & 6 & \\
\hline Subtotal & 624 & 261 & 92 & \\
\hline Reconstruction & & & & 0.458 \\
\hline Billroth-I & 369 & 173 & 55 & \\
\hline Billroth-II & 246 & 87 & 36 & \\
\hline Roux-en-Y & 57 & 25 & 7 & \\
\hline Lymph node dissection & & & & 0.461 \\
\hline D1+ & 33 & 19 & 4 & \\
\hline D2 & 639 & 266 & 94 & \\
\hline Retrieved lymph node (number) & $37.5 \pm 13.9$ & $34.7 \pm 14.2$ & $33.5 \pm 12.3$ & 0.002 \\
\hline First flatus time (days) ${ }^{*}$ & $2.8 \pm 1.1$ & $3.0 \pm 1.1$ & $2.9 \pm 1.1$ & 0.209 \\
\hline Post-operative transfusion & 20 & 8 & 6 & 0.231 \\
\hline Median follow-up duration (months, range) & $52.1(1.5-136.0)$ & $52.3(0.7-135.3)$ & $42.7(4.7-117.4)$ & 0.033 \\
\hline
\end{tabular}

*All values are the means and standard deviations.

Group 1: $<65$ years, young age; Group 2: 65-74 years, elderly age; Group 3: $\geq 75$ years, very elderly age.

Table 3 Postoperative complications among the three groups

\begin{tabular}{lcccc}
\hline & $\begin{array}{c}\text { Group 1 } \\
(\mathbf{n}=\mathbf{6 7 2})\end{array}$ & $\begin{array}{c}\text { Group 2 } \\
(\mathbf{n}=\mathbf{2 8 5})\end{array}$ & $\begin{array}{c}\text { Group 3 } \\
(\mathbf{n}=\mathbf{9 8})\end{array}$ & $\begin{array}{c}\boldsymbol{P} \\
\text { value }\end{array}$ \\
\hline Complications (\%) & $62(9.2)$ & $26(9.1)$ & $18(18.4)$ & 0.008 \\
Wound infection & 6 & 5 & 3 & \\
Intra-abdominal abscess & $6\left(1^{*}\right)$ & 1 & 0 & \\
Intra-abdominal bleeding & 6 & 3 & 0 & \\
Intra-luminal bleeding & 12 & 3 & 5 & \\
Postoperative ileus & 9 & 2 & 2 & \\
Bile leakage & 0 & 1 & 0 & \\
Duodenal stump leakage & $5\left(4^{*}\right)$ & $2\left(1^{*}{ }^{* *}\right)$ & $1\left(1^{*}\right)$ & \\
Esophagojejunostomy & & 1 & & \\
leakage & & & & \\
Acute pancreatitis & 2 & 0 & 0 & \\
Pulmonary disease & 9 & 4 & 1 & \\
Urinary complication & 2 & 1 & 3 & \\
Hepatic complication & 0 & 1 & 0 & \\
Cardiac disease & 0 & 0 & 1 & 1 \\
A-loop syndrome & 0 & 0 & $1\left(1^{* *}\right)$ & 0 \\
Multi-organ failure & 5 & 1 & 1 & \\
Others & & & & \\
\hline
\end{tabular}

*Reoperation; **Mortality.

Group 1: $<65$ years, young age; Group 2: 65-74 years, elderly age; Group 3: $\geq 75$ years, very elderly age. cholecystectomy, the post-operative complication and mortality rates were higher in elderly patients than in younger patients, and more comorbidities among elderly patients, especially coronary artery disease, accounted for this adverse outcome [22]. In a multicenter study of colorectal cancer, $85 \%$ of the elderly group had at least one cardiovascular risk factor [23]. In our study, we observed similar results with the proportion of comorbidities increasing as the age increased $(P<0.001)$.

Life expectancy has been increasing, and recently, numbers of elderly patients with gastric cancer who are

Table 4 Postoperative complications by the ClavienDindo classification

\begin{tabular}{|c|c|c|c|c|}
\hline & $\begin{array}{l}\text { Group } 1 \\
(n=672)\end{array}$ & $\begin{array}{l}\text { Group } 2 \\
(n=285)\end{array}$ & $\begin{array}{r}\text { Group } 3 \\
(n=98)\end{array}$ & $P$ value \\
\hline Minor complications & & & & 0.114 \\
\hline Grade I & 31 & 11 & 6 & \\
\hline Grade II & 18 & 10 & 7 & \\
\hline Major complications & & & & 0.113 \\
\hline Grade III-a & 7 & 1 & 2 & \\
\hline Grade III-b & 5 & 2 & 1 & \\
\hline Grade IV-a & 1 & 0 & 2 & \\
\hline Grade IV-b & 0 & 0 & 0 & \\
\hline Grade V & 0 & 2 & 0 & \\
\hline
\end{tabular}

Group 1: $<65$ years, young age; Group 2: 65-74 years, elderly age; Group 3: $\geq 75$ years, very elderly age. 
considered as candidates for LAG are expanding. However, the safety of LAG in elderly patients has not been proved because of the possible adverse hemodynamic and respiratory effects of the pneumoperitoneum on the limited cardiopulmonary reserve of these patients $[24,25]$. Pre-operative comorbidities were observed frequently in elderly patients undergoing conventional open gastrectomy [26,27]. The incidence of postoperative complications following open gastrectomy in elderly patients was also reported more frequently than in younger patients [26,27]. However, many reports have concluded that LAG is a feasible and safe procedure in elderly patients if the patients have been selected carefully and the procedure is performed by an experienced laparoscopic surgeon [28-30].

In the present study, although the number of retrieved lymph nodes in group 3 was less than in the other two groups $(P=0.002)$, the extent of lymph node dissection was not of statistical significance among the three groups $(P=0.461)$. Also, the median follow-up period in this group was shorter than in the other two groups $(P=0.033)$. The results reflect the fact that LAG is a more recently performed procedure, and more experience is being gained with laparoscopic surgery in very elderly patients. Nevertheless, despite these findings, the proportion of comorbidities increased as the age increased among the three groups. Further, our results showed that patients in group 3 ( $\geq 75$ years) frequently had a higher rate of postoperative complications than other groups. However, in order to assess the severity and incidence of postoperative complications among the three groups, we standardized and graded the postoperative complications according to the Clavien-Dindo classification system [17,18]. According to the Clavien-Dindo classification system, there was no statistically significant difference among the three groups. Moreover, when post-operative complications were considered, there was no statistically significant difference in post-operative transfusion rates $(P=0.231)$.

There have been many reports of LAG in elderly patients. However, most reports analyzed the postoperative complications in terms of the rate of complications $[10,11,26,29,30]$. In the present study, we considered the rate and severity of post-operative complications among the three groups. As a result, our retrospective study demonstrated that the postoperative complications occurred more frequently in very elderly patients undergoing LAG. However, in terms of the severity of postoperative complications for LAG in elderly and very elderly patients, there was no difference compared to other groups. These results showed that most of the postoperative complications in elderly and very elderly patients are minor complications according to the Clavien-Dindo classification system, which may be managed by conservative treatment with their age status taken into account.

Although this study is a retrospective study, with data prospectively collected and reviewed from the gastric cancer database of our institute, we propose that, in respect of the severity of post-operative complications, the post-operative complications of elderly and very elderly patients with gastric cancer who undergo LAG are no different than those in younger age groups.

\section{Conclusions}

Elderly patients undergoing gastric cancer operations are exposed to potential operative risks and may experience post-operative morbidity and mortality. Although the rate of post-operative complications in very elderly patients who undergo LAG may be relatively high, the severity of postoperative complications is of a similar degree to that of other age groups. In analyzing any study of postoperative complications in elderly patients who have undergone any operations, not only the rate of postoperative complications, but also the severity of postoperative complications, must be considered.

\section{Abbreviations}

LAG: Laparoscopy-assisted gastrectomy; BMI: Body mass index.

\section{Competing interests}

The authors declare that they have no competing interest.

\section{Authors' contributions}

KH Kim carried out data collection. MC Kim and GJ Jung helped draft the manuscript. All authors read and approved the final manuscript.

\section{Acknowledgments}

This work was supported by the Dong-A University research fund. All authors disclosed no financial relationships relevant to this publication.

Received: 1 December 2013 Accepted: 7 April 2014

Published: 16 April 2014

\section{References}

1. Korean statistical Information Service; 2012. [http://kosis.kr] Accessed 13 April 2014.

2. Korean Statistical Information Service; 2012. http://kosis.kr/statisticsList/ statisticsList_01List.jsp?vwcd=MT_ZTITLE\&parentld=A\#SubCont, Accessed 13 April 2014

3. United Nations Population Fund. State of World Population 2013; 2013 [http://www.unfpa.org/webdav/site/global/shared/swp2013/EN-SWOP2013final.pdf] Accessed 13 April 2014.

4. Hyung WJ, Kim SS, Choi WH, Cheong JH, Choi SH, Kim CB, Noh SH: Changes in treatment outcomes of gastric cancer surgery over 45 years at a single institution. Yonsei Med J 2008, 49:409-415.

5. Jeong O, Park YK: Clinicopathological features and surgical treatment of gastric cancer in South Korea: the results of 2009 nationwide survey on surgically treated gastric cancer patients. J Gastric Cancer 2011, 11:69-77.

6. Kim MC, Kim KH, Kim HH, Jung GJ: Comparison of laparoscopy-assisted by conventional open distal gastrectomy and extraperigastric lymph node dissection in early gastric cancer. J Surg Oncol 2005, 91:90-94.

7. Adachi Y, Suematsu T, Shiraishi N, Katsuta T, Morimoto A, Kitano S, Akazawa K: Quality of life after laparoscopyassisted Billroth I gastrectomy. Ann Surg 1999, 229:49-54.

8. Kim YW, Baik YH, Yun YH, Nam BH, Kim DH, Choi IJ, Bae JM: Improved quality of life outcomes after laparoscopy-assisted distal gastrectomy for 
early gastric cancer: results of a prospective randomized clinical trial. Ann Surg 2008, 248:721-727.

9. Ceulemans R, Al-Ahdab N, Leroy J, Garcia A, Dutson E, Rubino F, Simone M, Mutter D, Marescaux J: Safe laparoscopic surgery in the elderly. Am J Surg 2004, 187:323-327.

10. Mochiki E, Ohno T, Kamiyama Y, Aihara R, Nakabayashi T, Asao T, Kuwano H: Laparoscopy-assisted gastrectomy for early gastric cancer in young and elderly patients. World J Surg 2005, 29:1585-1591.

11. Yasuda K, Sonoda K, Shiroshita H, Inomata M, Shiraishi N, Kitano S: Laparoscopically assisted distal gastrectomy for early gastric cancer in the elderly. Br J Surg 2004, 91:1061-1065.

12. Endo S, Yoshikawa Y, Hatanaka N, Tominaga H, Shimizu Y, Hiraoka K, Nishitani A, Irei T, Nakashima S, Park MH, Takahashi H, Wakahara M, Kamiike W: Treatment for gastric carcinoma in the oldest old patients. Gastric Cancer 2011, 14:139-143.

13. Ishigami S, Natsugoe S, Hokita S, Iwashige H, Saihara T, Tokushige M, Aikou T: Strategy of gastric cancer in patients 85 years old and older. Hepatogastroenterol 1999, 46:2091-2095.

14. Kim KH, Kim MC, Jung GJ, Kim HH: Long-term outcomes and feasibility with laparoscopy-assisted gastrectomy for gastric cancer. J Gastric Cancer 2012, 12:18-25.

15. Edge SB, Byrd DR, Compton CC, Fritz AG, Greene FL, Trotti A: AJCC Cancer Staging Manual. 7th edition. New York: Springer; 2010.

16. Japanese Gastric Cancer Association: Japanese gastric cancer treatment guidelines 2010 (ver. 3). Gastric Cancer 2011, 14:113-123.

17. Clavien PA, Barkun J, de Oliveira ML, Vauthey JN, Dindo D, Schulick RD, de Santibañes E, Pekolj J, Slankamenac K, Bassi C, Graf R, Vonlanthen R, Padbury R, Cameron JL, Makuuchi M: The Clavien-Dindo classification of surgical complications: five-year experience. Ann Surg 2009, 250:187-196.

18. Dindo D, Demartines N, Clavien PA: Classification of surgical complications: a new proposal with evaluation in a cohort of 6336 patients and results of a survey. Ann Surg 2004, 240:205-213.

19. Korea Development Institute; 2012. [http://www.kdi.re.kr/kdi_eng/main.jsp] Accessed 13 April 2014.

20. Evers BM, Townsend CM Jr, Thompson JC: Organ physiology of aging. Surg Clin North Am 1994, 74:23-39.

21. Winslet MC, Mohsen YM, Powell J, AllumW H, Fielding JW: The influence of age on the surgical management of carcinoma of the stomach. Eur J Surg Oncol 1996, 22:220-224.

22. Brunt LM, Quasebarth MA, Dunnegan DL, Soper NJ: Outcomes analysis of laparoscopic cholecystectomy in the extremely elderly. Surg Endosc 2001, 15:700-705.

23. Marusch F, Koch A, Schmidt U, Steinert R, Ueberrueck T, Bittner R, Berg E, Engemann R, Gellert K, Arbogast R, Körner T, Köckerling F, Gastinger I, Lippert H, Working Group Colon/Rectum Cancer: The impact of the risk factor "age" on the early postoperative results of surgery for colorectal carcinoma and its significance for perioperative management. World $J$ Surg 2005, 29:1013-1021.

24. Joris JL, Noirot DP, Legrand MJ, Jacquet NJ, Lamy ML: Hemodynamic changes during laparoscopic cholecystectomy. Anesth Analg 1993, 76:1067-1071.

25. Harris SN, Ballantyne GH, Luther MA, Perrino AC Jr: Alterations of cardiovascular performance during laparoscopic colectomy: a combined hemodynamic and echocardiographic analysis. Anesth Analg 1996, 83:482-487.

26. Wu CW, Lo SS, Shen KH, Hsieh MC, Lui WY, P'Eng FK: Surgical mortality, survival, and quality of life after resection for gastric cancer in the elderly. World J Surg 2000, 24:465-472.

27. Bittner R, Butters M, Ulrich M, Uppenbrink S, Beger HG: Total gastrectomy. Updated operative mortality and long-term survival with particular reference to patients older than 70 years of age. Ann Surg 1996, 224:37-42.

28. Koeda K, Nishizuka S, Wakabayashi G: Minimally invasive surgery for gastric cancer: the future standard of care. World I Surg 2011, 35:1469-1477
29. Tokunaga M, Hiki N, Fukunaga T, Miki A, Ohyama S, Seto Y, Yamaguchi T: Does age matter in the indication for laparoscopy-assisted gastrectomy? $J$ Gastrointest Surg 2008, 12:1502-1507.

30. Hwang SH, Park Do J, Jee YS, Kim HH, Lee HJ, Yang HK, Lee KU: Risk factors for operative complications in elderly patients during laparoscopyassisted gastrectomy. J Am Coll Surg 2009, 208:186-192.

doi:10.1186/1477-7819-12-97

Cite this article as: Kim et al: Is the rate of postoperative complications following laparoscopy-assisted gastrectomy higher in elderly patients than in younger patients? World Journal of Surgical Oncology 2014 12:97.

\section{Submit your next manuscript to BioMed Central and take full advantage of:}

- Convenient online submission

- Thorough peer review

- No space constraints or color figure charges

- Immediate publication on acceptance

- Inclusion in PubMed, CAS, Scopus and Google Scholar

- Research which is freely available for redistribution
C Biomed Central 